\title{
LA ASIGNATURA DE HISTORIA Y LA ENSEÑANZA DE LOS DERECHOS HUMANOS DE LA MUJER EN EL CONTEXTO DE UNA NUEVA LEY EDUCATIVA
}

\author{
Manuel Barreiro Mariño ${ }^{1}$ \\ Universidad Autónoma de Madrid
}

Recibido 31/03/2020 Aceptado 22/05/2020

\begin{abstract}
A razón de la publicación de un nuevo proyecto de ley educativo, LOMLOE, nace en la comunidad educativa una preocupación siempre presente a lo largo de las diferentes leyes educativas aprobadas en España, la Educación en Derechos Humanos, en adelante EDH, y su escasa presencia en la Educación formal. Esto es debido a las escasas modificaciones que la nueva ley hace a este respeto. Por este motivo, desde esta investigación hemos querido abordar el rol que la EDH ocupa dentro de los contenidos de Historia, como asignatura idónea para la enseñanza de Derechos Humanos, y más particularmente los derechos relativos a la mujer, la gran olvidada, para así mostrar la necesidad de una reforma profunda en materia de EDH.
\end{abstract}

5 Following the publication of a new educational law project, LOMLOE, an ever-present concern existent throughout the different educational laws approved in Spain, the Human Rights Education, henceforth HRE, and its scarce presence in formal education, is born in the educational community This is due to the few modifications that the new law makes in this regard. For this reason, from this research we have wanted to address the role that HRE occupies within the contents of History, as an ideal subject for the teaching of Human Rights, and more particularly the rights related to women, the great forgotten, in order to show the need for a profound reform in the field of HRE.

\section{DOI}

https://doi.org/10.15366/didacticas2020.22.003

PALABRAs Clave

Educación; Ley; Derechos Humanos; Historia; Mujer. 


\section{INTRODUCCIÓN}

El 7 de enero de este año 2020 se daba comienzo en España a una nueva legislatura que designaba a Pedro Sánchez como presidente proclamado, no en funciones (Menéndez, 2020), produciéndose un cambio ideológico en el gobierno con respecto al último presidente proclamado, Mariano Rajoy (Presidencia de Gobierno, s.f.). A razón de este cambio de gobierno, se han iniciado ya los primeros pasos para aprobar una nueva ley educativa, conocida como LOMLOE (Ministerio de Educación y Formación Profesional, 2020), que sustituya a la actual ley vigente, la LOMCE (2013).

El inicio de una nueva reforma educativa vuelve a traer a colación un asunto muy presente en el ámbito educativo en España como es la inestabilidad legislativa que padece la educación. Una inestabilidad legislativa que tiene su explicación en el hecho de que con este nuevo proyecto de ley, LOMLOE (2020), son ya ocho las leyes de educación que han regido el sistema educativo español desde el comienzo de la democracia en España en 1978.

La aprobación, hasta ahora, de hasta siete leyes desde 1978 hasta la actualidad ha traído como consecuencia que los planes de educación hayan cambiado reiteradamente a lo largo de estos años; siendo continuo el cambio en los programas y contenidos de las asignaturas, la variación en los años de duración y por supuesto modificándose el propio modelo de formación que recibe el alumnado. Todo ello conlleva a su vez, atendiendo a los criterios de González y Sanz (2016), que se propicie en el ámbito de la Educación "una sensación de provisionalidad e indefinición sobre los aspectos esenciales del sistema. Y contribuye a generar desorientación e incertidumbre entre los miembros de la comunidad educativa, especialmente familias y profesores, y la sociedad en su conjunto" (p. 8).

Dichos cambios tienen su principal razón en causas ideológicas, pues la derogación de una ley y la aprobación de una nueva se ha producido en España siempre a razón de un cambio de gobierno. Por ello, la aprobación de una nueva ley, con fecha de caducidad relativamente próxima, no hace sino aumentar la preocupación para aquellas y aquellos que nos dedicamos a la Educación, pues la continua modificación legislativa profundiza esta situación de inestabilidad, perjudicando esto notablemente a la calidad de la enseñanza ofrecida en España.

Será precisamente el nacimiento de la LOMLOE (2020) producto de esta realidad cambiante, concibiéndose dicha ley con el objetivo prioritario de derogar los principales y más polémicos aspectos de su ley predecesora, la LOMCE (2013).

Uno de estos aspectos a los que hacemos mención y que ha sido considerado mas polémico, y, a la vez, que más se ha resentido con la aprobación de la LOMCE, ha sido el rol que dicha ley ha otorgado a la Educación en Derechos Humanos (Amnistía Internacional, 2013 y Montes, 2014), en adelante EDH. El caso más significativo es la eliminación de la asignatura de Educación para la Ciudadanía y los Derechos Humanos, la cual profundizaba a través de sus contenidos en temas tales como la igualdad de género, los derechos LGTBI, el medioambiente, etc., y su substitución por las materias de Valores Sociales y Cívicos 
para la Educación Primaria y la materia de Valores Éticos para la Educación Secundaria Obligatoria. Ambas materias a diferencia de la Educación para la Ciudadanía y los Derechos Humanos no son obligatorias, sino que se presentan como optativa a la materia de religión. Esto trae como consecuencia que muchos alumnos/as puedan salir de la educación primaria y secundaria sin haberse formado en temas de tal relevancia para comprender y enfrontarse al mundo actual, como son los DDHH y los Valores Cívicos. Es por ello, que la LOMCE merma considerablemente la adquisición de valores democráticos y de justicia al eliminar la materia de Educación para la Ciudadanía y los Derechos Humanos del sistema educativo.

En este mismo sentido, la LOMCE realiza modificaciones en cuanto a la situación de la materia de filosofía dentro de la Educación secundaria, haciendo desaparecer la materia de Ética y Ciudadanía, materia obligatoria en $4^{\circ}$ de ESO con la LOE, y la substituye por una materia cuyo nombre es Filosofía, la cual se presenta como optativa, siendo la única materia sobre filosofía que se cursa en toda la ESO. Por su parte, la asignatura de Historia de la Filosofía de $2^{\circ}$ de Bachillerato se convierte también en materia optativa, cuando con la LOE era obligatoria, siendo entonces Filosofía de $1^{\circ}$ de Bachillerato la única materia obligatoria en toda la Educación secundaria. La relegación de los conocimientos filosóficos a la condición de opcionales tiene como consecuencia que se prive a muchas/os alumnas/os de la adquisición de saberes que favorecen "la reflexión personal sobre otras concepciones ideológicas y la crítica social" (Bayona, 2013, p.15).

Otro hecho significativo es el caso de la eliminación de la materia de Ciencias para el Mundo Contemporáneo, propia de la modalidad de Humanidades y Ciencias Sociales de Bachillerato, cuyos contenidos estaban dirigidos a educar en conceptos científicos básicos a las alumnas/os pertenecientes a esta modalidad. Esta asignatura era conocida por propiciar el debate sobre diversos temas morales de la actualidad.

En definitiva, si atendemos a la distribución de las asignaturas que ha hecho la LOMCE tras su aprobación, podemos concluir que se ha desplazado de la escena principal, o directamente eliminado, la gran mayoría de materias destinadas a favorecer el desarrollo del intelecto, el carácter crítico en la o el estudiante y el conocimiento práctico de los DDHH.

Esto ha supuesto un verdadero varapalo para el estado de la educación en España, pues es la EDH uno de los principales pilares y objetivos en los que sustenta toda educación de calidad en la actualidad. Esto se debe al hecho de que la EDH se comporta dentro de la educación como "un bien público y una inversión continua para producir sociedades caracterizadas por principios de Derechos Humanos tales como la no discriminación, inclusión y participación, y el estado de derecho" (UNESCO, 2015, p.10), promoviendo entre las alumnas y alumnos un conocimiento útil que las y los hace conscientes de sus derechos y de los de la comunidad, como seres humanos todos, y les ayuda a tomar consciencia del papel activo que deben jugar en la defensa y promoción del cumplimiento de los DDHH, no solo los suyos propios sino los de toda la sociedad, en aras de instaurar una mejor convivencia universal. 
Es entonces, a razón de todo lo anterior, y justamente en este contexto actual marcado por una nueva reforma educativa, donde desde este artículo se plantea si realmente se está produciendo un cambio significativo en la mejora de la educación a raíz de este nuevo proyecto de ley. Pues si bien es cierto que desde la nueva ley se apuntan cambios al respecto de la situación de la EDH dentro del sistema educativo, véase la incorporación de nuevas temáticas como la perspectiva de género o educación en valores cívicos y para el desarrollo sostenible 2030 (Farreras, 2020) o el hecho de que "la Educación en Valores Cívicos y Éticos pasará a ser obligatoria para todos los alumnos en un curso de primaria y en otro curso de secundaria, aún por determinar” (Torres Menárguez, 2020), y aún considerando positivos estos cambios, estimamos que estas modificaciones no son del todo ambiciosas, no solventan de todo el problema, pues aún no se habla en el contexto de esta nueva ley, partiendo de que no se ha detallado aún de todo esta, de una reforma significativa de los contenidos designados para las asignaturas de dos áreas como son la Filosofía y la Historia (LOMLOE, 2020), que por su naturaleza son idóneas para la enseñanza de Derechos Humanos, y que por la composición y clasificación que se le ha otorgado a lo largo de las diferentes leyes que se han establecido durante el actual período democrático, su enseñanza ha sigo relegada a un proceso de aprendizaje mayoritariamente memorístico, obstaculizando esto notablemente el desarrollo de un proceso de enseñanza-aprendizaje significativo a través de dichas materias académicas.

Especial es el caso del área de Historia, cuyas leyes educativas le han otorgado un rol educativo dirigido, aún hoy en día, a la promoción de la identidad nacional, primando estos contenidos sobre los universales (Barton, 2010); muy alejado de la realidad que viven las alumnas y los alumnos, puesto que la enseñanza de historia sigue caracterizándose hoy en día por la exposición de contenidos históricos acabados que prestan especial atención en un pasado muy alejado del presente del alumnado y dejan poco espacio a la enseñanza de los hechos más recientes (Pagès 1998 y 2009 y Valls y López Facal, 2010); donde se obvia uno de los grandes objetivos de la enseñanza de historia, como es el desarrollo del pensamiento crítico, siendo escasos los conocimientos habidos sobre como aplicar el desarrollo del pensamiento crítico sobre el alumnado en la materia de Historia (Miralles, Molina y Ortuño, 2011); y, donde ha predominado el eurocentrismo y el androcentrismo a la hora de narrar la historia (García Luque, 2015); entre otros muchos factores que han afectado a la enseñanza de historia desde el ámbito legislativo y constitucional.

La determinada organización y entendimiento que se ha tenido por parte de los diferentes ministros y ministras de Educación, y sus gabinetes, al respecto de la materia de Historia, han traído como consecuencia que haya obstaculizado a lo largo de las diversas leyes educativas un aprendizaje significativo de los conocimientos históricos, viéndose afectado uno de los principales objetivos, o que al menos debiera ser, de la enseñanza de historia, la educación en el conocimiento práctico de los Derechos Humanos. Esto tiene su razón en que la finalidad última de la enseñanza de historia debe ser la comprensión de la 
sociedad, con el objetivo de poder desarrollar los estudiantes un pensamiento social y crítico que les permita participar en la ciudadanía desde una posición de entendimiento y discernimiento (De Alba, García y Santiesteban, 2012 y López Facal y Valls, 2012). Puesto que la historia nos ofrece la perspectiva social, a través de la comparación entre el pasado y el presente, lo que nos aporta un inmejorable punto de vista de "la génesis, desarrollo y posibilidades de la participación ciudadana” (De Alba, García y Santiesteban, 2012, p.14). Es precisamente por esa capacidad de la historia, "como ejercicio de análisis de problemas de las sociedades de otros tiempos, ayuda a comprender la complejidad de cualquier acontecimiento, de cualquier fenómeno social-político actual y de cualquier proceso histórico mediante el análisis de causas y consecuencias" (Prats y Santacana, 2011, p. 28) que tiene la responsabilidad de "abordar las causas profundas de las violaciones de derechos humanos" para empoderar a las personas a través de la creación de un entorno propicio al pensamiento crítico para que reflexionen sobre sus propios valores y actitudes y, en definitiva, modifiquen su propia conducta (Amnistía Internacional, s.f.).

A este respecto, la perspectiva androcéntrica será uno de los problemas más importantes, sino el que más, a la hora de afrontar la enseñanza de historia, pues esto afecta a uno de los derechos humanos más importante, por afectar a la mitad de la población, y más violado, la igualdad de género (García Luque, 2015 y Pérez López, 2011). Razón por la cual, desde este artículo, en pleno contexto de una reforma educativa eminente, hemos querido centrar nuestra atención en cual es el mensaje educativo que se transmite desde la enseñanza de historia en la Educación obligatoria acerca del papel de la mujer en la Historia Contemporánea de España, pues solo a partir del conocimiento profundo de la situación podremos saber cuales son los aspectos que necesitan ser modificados o mejorados; lo cual debe ser fundamental a la hora de afrontar una reforma legislativa que pretenda lograr una mejora real en la calidad de nuestra Educación.

Para llevar a cabo esto, realizamos un estudio de caso focalizado en la influencia que el currículo de la LOMCE de $4^{\circ}$ de ESO de la materia de Geografía e Historia, donde se aborda el estudio de la Historia Contemporánea universal, y el libro asignado para ese curso tiene en la enseñanza del papel de la mujer a lo largo de la Historia Contemporánea de España en las aulas de $4^{\circ}$ de ESO del Instituto de Secundaria Arcebispo Xelmírez I, de Santiago de Compostela. Hemos querido centrar nuestra atención en el curso de $4^{\circ}$ de ESO, con la intención de conocer cuales son los contenidos y aprendizajes que reciben los alumnos/as acerca del papel de la mujer en nuestra historia reciente en el último curso de la Educación obligatoria, siendo para muchos/as el último curso de su formación en Historia. Es decir, con este estudio hemos pretendido saber con que conocimientos y visión sobre la figura de la mujer en la Historia actual de España abandonan las alumnas/os su formación dentro de la Educación Secundaria Obligatoria.

Cabe dejar constancia que a pesar de tratarse de un estudio de caso, esta investigación parte de un estudio general como es el análisis del currículo de la LOMCE de $4^{\circ}$ de ESO, que afecta a todos y cada uno de los centros de secundaria de España, a excepción de los 
contenidos sobre Galicia, y parte del estudio de un manual escolar, el más empleado en Galicia, cuyos contenidos no distan mucho de los del resto de España, pues su creación e influencia parte de los contenidos de la LOMCE, fuente común de todas y cada una de las editoriales de estos libros (Pérez López, 2011). Por tanto, los resultados y principales apreciaciones de esta investigación podrán ser comparados y compartidos con todos aquellos estudios que centren este mismo foco de investigación en otras regiones o ciudades de España.

Antes de finalizar esta introducción, solo cabe decir que si hemos querido centrar nuestro estudio en un centro en particular, es por llevar nuestro estudio a la realidad diaria de las aulas, para conocer como el currículo y el manual influyen en el conocimiento que los profesores/as de Historia enseñan al alumnado en materia de mujer y su rol en nuestro pasado reciente.

\section{EL CURRÍCULO DE GEOGRAFÍA E HISTORIA DE 4ㅇ DE ESO (LOMCE)}

El currículo de la materia de Geografía e Historia de $4^{\circ}$ de ESO empleado para conocer cual es la presencia de la mujer en el relato histórico diseñado por parte de las administraciones es el Currículo Educación Secundaria Obrigatoria elaborado por la Consellería de Cultura, Educación e Ordenación Universitaria de la Xunta de Galicia (Decreto 86/2015, 2015), puesto que las administraciones autonómicas son en la LOMCE las encargadas de complementar los contenidos del bloque de asignaturas troncales (2013), como es el caso de Geografía e Historia de $4^{\circ}$ de ESO; es decir, son las administraciones autonómicas las responsables de las últimas modificaciones y añadidos en la elaboración del currículo educativo.

Para el estudio del rol que tiene la figura de la mujer en la narración histórica en la LOMCE (2013), hemos analizado los contenidos, los criterios de evaluación y los estándares de aprendizaje del currículo de $4^{\circ}$ de ESO de Geografía e Historia en la procura de todos aquellos elementos que hagan referencia específica al papel de la mujer en la historia. El hecho de centrar nuestra atención en aquellos elementos que se focalicen en la figura de la mujer se debe a la perduración, hasta nuestros días, tanto en la enseñanza de historia como en la historiografía de una perspectiva meramente androcéntrica a la hora de narrar los acontecimientos históricos. Una narración que se ha centrado en el ámbito educativo en la enseñanza de la Historia Política principalmente, donde la mujer, debido al orden patriarcal establecido, ha tenido poca presencia y se relega, por tanto, en el relato histórico a un papel secundario (Sant y Pagès, 2011 y García Luque, 2015). A razón de esto, la procura de dichos contenidos específicos tiene su fundamento en conocer si desde las autoridades educativas se está revirtiendo la situación general de desconocimiento sobre la historia de la mujer, la cual ha venido marcada por el predominio de la visión androcéntrica a lo largo de los años de enseñanza de la historia. 
Desafortunadamente, el análisis del currículo de $4^{\circ}$ de ESO de Geografía e Historia (Decreto 86/2015, 2015) no contradice precisamente el dominante modelo androcéntrico de enseñanza de la historia, pues estudiando la totalidad del plan de estudios para esta materia son solo tres los elementos que mencionan específicamente la figura de la mujer, y están asociados a los estándares de aprendizaje. Esto contrasta con el gran número de contenidos establecidos para el curso de $4^{\circ}$ de ESO, vinculados la mayoría a la Historia Política, en la cual, recordemos, prevalece una jerarquía, casi, exclusivamente patriarcal a lo largo de la Historia Contemporánea hasta la actualidad, que otorga a la mujer a un rol muy minoritario en el proceso de enseñanza-aprendizaje de la Historia Contemporánea universal.

Por otra parte, los tres elementos referentes a la historia de la mujer dentro del currículo de Geografía e Historia de $4^{\circ}$ de ESO (Decreto 86/2015, 2015) se comprenden dentro de la Historia Social, entendiendo, como lo hacía Eric Hobsbawn, Historia Social como el estudio conjunto de la sociedad y la economía (Valerio Ulloa, 2013). De este modo, en el relato histórico, proyectado desde el ámbito educativo, sobre la mujer sigue perviviendo su asociación casi exclusiva a la Historia Social, en la cual se aborda el papel de la mujer vinculado únicamente al ámbito privado, no haciendo ningún tipo de distinción de clase social entre ellas, y calificándolo siempre como grupo oprimido, lo cual aleja este relato del conocimiento de la realidad de la mujer en la Historia (Vega, 2002; Pérez López, 2011 y García Luque, 2015), pues disponemos de múltiples fuentes documentales actualmente para poder afirmar con rotundidad que "en el pasado y en el presente el rol de las mujeres ha sido fundamental en la evolución de las sociedades” (Sant y Pagés, 2011, p. 139).

Entonces, y partiendo del hecho que solo a través del manual escolar podremos saber en detalle cuales son los contenidos y tratamiento de la mujer en las aulas, si que podemos afirmar que el currículo establece un contexto nada favorable a revertir la situación del tratamiento de la mujer en la enseñanza de Historia. Pues la escasa presencia de contenidos específicos sobre el rol de la mujer entre los múltiples contenidos habidos, donde como ya vimos anteriormente predomina la visión androcéntrica, dificulta más que notablemente que el alumnado pueda llegar a un conocimiento real y profundo sobre la realidad de la mujer en la historia, pues no olvidemos que el currículo es el encargado de establecer las bases del proceso educativo en las aulas. Ejemplo de esto, es el hecho de que en el currículo de $4^{\circ}$ de ESO de Geografía e Historia (Decreto 86/2015, 2015) no se haga mención específica, entre otros, a cuestiones como las luchas y cambios políticos y sociales llevados a cabo por las mujeres a principios del siglo XX o a la figura de la mujer en el ámbito político de la II República española, siendo ambos parte de los acontecimientos más significativos que tuvieron lugar en el pasado siglo. Por consiguiente, si bien es cierto que solo el manual escolar, analizado a continuación, nos ayudará a comprender en profundidad si el tratamiento de la mujer es el adecuado en las aulas $4^{\circ}$ de ESO, pero la verdad es que analizando las bases educativas que establece el currículo de la LOMCE, consideremos que 
para nada se favorece un tratamiento de la mujer en la historia equitativo al del hombre por parte las administraciones educativas gubernamentales.

\section{EL MANUAL ESCOLAR DE 4 DE ESO DE GEOGRAFÍA E HISTORIA}

El manual escolar es, casi siempre, la principal fuente de información empleada en las aulas para allegar al conocimiento de la historia a las alumnas y alumnos; por tanto, el contenido y el modo de comunicar el mismo serán totalmente influyentes en la manera que el o la estudiante aprende el relato histórico. Por ello, en este artículo hemos analizado el libro de texto de la asignatura de Geografía e Historia de $4^{\circ}$ de ESO escogido por el departamento de Geografía e Historia del Instituto Arcebispo Xelmirez I con la intención de conocer como es presentada la información histórica y cual es el tratamiento que recibe la mujer en el relato histórico en el principal material de estudio usado en el día a día de las aulas del centro de secundaria compostelano. Cabe aclarar que en ningún momento mencionaremos el título del manual escolar no solo para así evitar toda posible polémica o perjuicio a la editorial, sino también porque consideremos firmemente que todas las editoriales tienen una fuente común para la elaboración de sus libros, la LOMCE (2013), por tanto, los contenidos presentes en estos son los mismos, o muy similares.

Para el análisis de este manual hemos empleado el método utilizado por Pérez López (2011) en su estudio El sexismo en los manuales escolares de Ciencias Sociales de la ESO. Este método consiste en analizar el contenido presente en el libro, el lenguaje empleado por este y las imágenes utilizadas para ilustrar los contenidos históricos, en busca de todo aquel elemento que promueva una perspectiva androcéntrica a la hora de narrar los acontecimientos ocurridos durante la Historia Contemporánea universal.

El primer elemento a estudiar en el manual será, por tanto, el contenido. Con contenido hacemos referencia a "el corpus textual escrito en cada libro de texto en el que se recoge el discurso considerado por los autores y autoras, lo que el alumnado termina asumiendo como verdad absoluta” (Pérez López, 2011, p. 66).

El contenido del manual escolar de $4^{\circ}$ ESO de Geografía e Historia destacará en los primeros temas, los asociados al siglo XVIII y primera mitad del XIX, por la escasísima presencia que la mujer tiene dentro del relato histórico. Esto se aprecia a la hora de observar los ejemplos empleados por el manual, donde raramente aparece mencionada alguna mujer, algo que contrasta de manera notoria con la historiografía actual la cual nos muestra que la mujer ha tenido un peso importante en el devenir histórico de estos siglos (García Luque, 2015).

Mención a parte merece el caso de los apartados dedicados a la ciencia y a las innovaciones científicas donde no se cita para nada el caso de ninguna mujer, dando esto a entender que la mujer no tuvo parte ninguno en los avances tecnológicos de esa época. 
Otra cuestión a destacar es el hecho de que en varias ocasiones a lo largo de la narración de estos dos siglos, la presencia de la mujer en las imágenes no será correspondida con su presencia en la explicación textual, obstaculizando al alumnado profundizar y detallar acerca de la información que se les presenta a través de las ilustraciones. Ejemplo claro de ello es el caso del trabajo de la mujer durante la Revolución Industrial, no haciendo mención ninguna en el texto a pesar de la existencia de una imagen que nos aporta una idea superficial de en que consistía el trabajo femenino durante ese período, lo que es claramente insuficiente para que el alumnado pueda conocer realmente cual era el rol de la mujer en el ámbito laboral en este período histórico.

La presencia y tratamiento de la historia de la mujer en los temas que abordan desde la segunda mitad del siglo XIX hasta la actualidad mejorará con respecto a los anteriores temas, véase el caso de la mención particular de la evolución derecho político de las mujeres, la citación de mujeres y sus estudios en el ámbito de la ciencia, o la descripción de la inserción de la mujer al mundo laboral, entre otras temáticas. No obstante, estas cuestiones ocuparán un lugar muy minoritario en el discurso histórico empleado por el libro, predominando de manera notoria el tratamiento de la historia del hombre sobre el de la mujer.

Todo ello nos permite afirmar que tristemente hoy en día aún pervive en los manuales escolares, como es el caso de este manual en particular, la narración de los acontecimientos históricos desde una perspectiva mayoritariamente androcéntrica, que trae como consecuencia que en la enseñanza que se transmite a las nuevas generaciones sigue prevaleciendo un conocimiento sexista de la historia.

El segundo aspecto a estudiar sobre este libro es el referente al lenguaje empleado, con el fin de investigar si este lenguaje promueve o no un conocimiento sexista de la historia.

Lejos de querer entrar en este momento en un debate lingüístico, la razón es que tanto la lengua gallega, lengua en la que está escrita el manual, como la lengua española utilizan el masculino plural para comprender a ambos géneros, lo que se conoce como género no marcado (RAE, s.f.). En dicho manual el género no marcado es usado habitualmente a lo largo del mismo, y si bien es cierto que no incumple ninguna ley lingüística, consideramos que el uso de este género no solo, en concordancia con las palabras de Pérez López (2011), origina "equívocos importantes porque a veces esa palabra se referirá exclusivamente a los hombres, pero otras se referirá al conjunto de mujeres y hombres” (p. 70), sino que hace invisible a la mujer, sustentando el discurso androcéntrico de la historia que ya se manifestaba en los contenidos de este mismo manual. Especialmente cuando se usa el termino "hombres" para referirse tanto a mujeres como hombres, hecho que pasa más de una vez en dicho manual.

No obstante, es justo decir que aparte del tema del uso del género no marcado, el texto ha prestado atención en el aspecto del lenguaje a la hora de no promover un mensaje 
sexista, a excepción, eso si, de dos casos que sin ser una gran cantidad si que son significativos, pues en uno se hace alusión a Françoise d'Aubigné como la mujer de Luis XIV, subordinando su posición a la del monarca francés. Y en el otro se destaca la figura de Agustina de Aragón por el hecho de ser mujer, y no por el hecho de ser militar, como se hace con el resto de los hombres mencionados en este apartado cuando se habla de la guerra contra Francia de inicios del XIX.

Por todo ello, si bien es cierto que no podemos hablar de la utilización de un lenguaje descaradamente sexista, el hecho del uso del género no marcado en conjunto con el predominio de una perspectiva androcéntrica a la hora de relatar los contenidos promueve una enseñanza sexista de la Historia Contemporánea universal en las aulas de $4^{\circ}$ de ESO del Instituto Arcebispo Xelmirez, a través del manual aquí observado.

El último elemento a analizar serán las imágenes para conocer el mensaje visual que aporta este libro en relación a la figura de la mujer en la historia. Este es un elemento muy importante hoy en día, como bien dice Pérez López (2011), puesto que las nuevas tecnologías han implantado fuertemente en la sociedad la cultura gráfica, especialmente en los y las jóvenes.

Acorde al método de análisis de Pérez López (2011) nos encontramos que en el manual escolar de $4^{\circ}$ de ESO no solo es mucho mayor el número de imágenes de hombres que de mujeres, sino que las imágenes femeninas son en su mayoría ilustraciones donde la mujer aparece como objeto del arte. En algunas imágenes, pero de manera minoritaria, aparecen como reinas. Serán escasísimas en este libro las imágenes donde las mujeres aparecen asociadas al ámbito laboral o político.

La determinada elección y disposición de las ilustraciones por parte del manual transmiten un mensaje estereotipado, que junto a los contenidos y el lenguaje presentes, hacen pervivir en el proceso de enseñanza-aprendizaje de la historia una perspectiva androcéntrica que no solo contribuye al desconocimiento del papel real que jugaron las mujeres a lo largo de la Historia Contemporánea, sino que también contribuye a mantener en el pensamiento social la idea de la mujer como ser subordinado a los intereses del hombre. Es decir, desde el manual, como instrumento de enseñanza, se ampara, a través del conocimiento de la historia, la concepción sexista de la sociedad, en vez de combatirla.

\section{LA EXPERIENCIA DE LOS DOCENTES ACERCA DEL TRATAMIENTO DE LA MUJER EN LA ENSEÑANZA DE LA HISTORIA EN EL INSTITUTO ARCEBISPO XELMIREZ I}

Una vez analizados el currículo de $4^{\circ}$ de ESO de Geografía e Historia y el manual escolar del mismo curso, hemos querido conocer la visión y experiencia de los profesores/as del instituto Arcebispo Xelmirez I alrededor de la enseñanza de la mujer en las clases de 
Historia de $4^{\text {o }}$ de ESO mediante el uso de los contenidos dispuestos por el currículo y el manual escolar para ello.

A razón de esto, hemos creado un modelo de entrevista a través del cual comprender cual es la impresión de los y las docentes acerca de esta cuestión (ANEXO), pues son ellos y ellas quien tienen que trabajar diariamente en las aulas con los contenidos marcados por el currículo y por el manual. De este modo, hemos realizado dichas entrevistas, de modo individual, a los miembros del departamento de Geografía e Historia del Xelmirez I que imparten actualmente en $4^{\circ}$ de ESO, Fernando Prieto y Alba Domínguez.

La primera pregunta que les planteamos fue la siguiente: Según su experiencia, ¿Cuál es la presencia de la mujer en los contenidos designados por el currículo de la LOMCE para la asignatura de $4^{\circ}$ de ESO? ¿Considera que se trata de modo proporcionado a mujer y hombre en el relato histórico? ¿Por qué? ¿Y en el libro de texto empleado? (Anexo I).

Ambos docentes coincidieron en el sentido de sus respuestas, comentando los dos que tanto en el currículo como en el libro de texto la presencia de contenidos relativos a la historia de la mujer es casi nulo. Por tanto, ambos apuntan que para nada se trata de manera equitativa la historia de la mujer en relación a la historia del hombre. En cada una de las entrevistas se hace hincapié en el tratamiento que el manual hace de la historia de la mujer. Prieto destacará el hecho del poco espacio que se dedica al sufragismo en el manual de $4^{\circ}$ de ESO, mientras que Domínguez señalará al vocabulario y el lenguaje empleado en el libro como el principal indicativo de que la mujer es excluida de los principales contenidos presentes en este.

La segunda pregunta planteada fue: alrededor del tratamiento que recibe la mujer en los contenidos de Historia, tanto en el currículo como en el manual escolar, y partiendo de su experiencia, me gustaría que respondiese y justificase las respuestas a las siguientes preguntas:

- ¿Considera que en el relato histórico desarrollado por el manual predomina una visión androcéntrica?

- ¿Piensa que a través de los contenidos dispuestos por el currículo y por el manual el alumnado puede obtener un conocimiento adecuado sobre el papel de la mujer en la Historia Contemporánea universal? (ANEXO).

A la primera cuestión de esta segunda pregunta ambos afirmarán de manera rotunda que consideran que desde el manual se potencia una visión androcéntrica de la historia. Prieto justificará su respuesta señalando el poco espacio que las mujeres ocupan a lo largo de los contenidos, y que cuando se mencionan, véase el caso de las reinas, es porque "se asocian a ella valores y roles de género normalmente vinculados con los hombres de poder", tales como el liderazgo y el belicismo, lo cual nos alejan de una visión real del papel que jugaban en la historia la mayoría de las mujeres. Por su parte, Domínguez indica que esta visión androcéntrica del manual se percibe claramente en el hecho de que la figura de 
la mujer es asociada siempre en el libro a los colectivos oprimidos, obviando el verdadero rol que las mujeres tuvieron en la Historia Contemporánea.

A la segunda cuestión de la pregunta número dos de la entrevista (ANEXO), nuevamente, ambos docentes respondieron en el mismo sentido, negando que mediante los contenidos establecidos por el currículo de la LOMCE y por el manual escolar de $4^{\circ}$ de ESO se pueda alcanzar un conocimiento profundo y verdadero de la historia de la mujer en el período contemporáneo. Domínguez considera que esto se debe principalmente al hecho de que el manual aborda la historia de la mujer de un modo marginal, siempre, o casi siempre, al final del libro y en un espacio pequeño, cuando lo correcto sería que desde el libro se propiciase un tratamiento transversal de la historia de la mujer y del hombre en todos y cada uno de los contenidos existentes.

La tercera pregunta que se les presentó fue: ¿Ha añadido o modificado algunos o todos los contenidos que existen en el libro con respecto al papel de la mujer en la Historia? ¿Por qué?(ANEXO).

Tanto Domínguez como Prieto reconocieron haber añadido contenidos al temario ya existente, introduciendo ambos trabajos de libre elección y debates acerca de diversas temáticas relativas a la historia de la mujer tales como el sufragismo, el feminismo o la mujer en el ámbito laboral. No obstante, Prieto considera que estas modificaciones no son suficientes para equilibrar el tratamiento de la mujer con el del hombre en las aulas de Historia, aclarando que el ingente número de contenidos dispuestos en el manual y en el currículo y el escaso tiempo del que disponen para su enseñanza impide que se pueda llevar a cabo un tratamiento de la historia de la mujer mucho más profundo de lo que el manual y el tiempo de clases posibilita.

Para finalizar la entrevista se les pregunta a ambos acerca del currículo de la LOMCE y su posible modificación al respecto de la aprobación de una nueva ley educativa: solo si usted lo considerara necesario, y atendiendo únicamente al diseño del currículo oficial de Historia por parte de las autoridades gubernamentales competentes ¿Qué consideraría necesario reformar en el diseño del área de Historia para revertir el determinado tratamiento que recibe la mujer en el relato histórico?(ANEXO).

Fernando Prieto considera necesaria la reforma del currículo, y señala que no sería un proceso complicado el que implica esta reforma, bastaría solo con introducir "la perspectiva histórica de la mujer en cada período, algo que ahora no se hace”. Del mismo modo, Alba Domínguez también considera precisa la reforma del currículo y apunta que dicha reforma debe focalizarse en modificar el vocabulario y lenguaje empleado por el currículo de manera que se eduque al alumnado de Historia en el conocimiento del verdadero rol que ha ocupado la mujer en todos y cada uno de los acontecimientos de la Historia Contemporánea, como "motor, junto al hombre, en todos y cada uno de los hechos históricos acontecidos". 


\section{CONCLUSIONES}

El análisis del currículo de Geografía e Historia de 4º de ESO (Decreto 86/2015, 2015), del manual escolar empleado en $4^{\circ}$ de ESO en el Instituto Arcebispo Xelmirez I de Santiago de Compostela y de la experiencia de los profesores del centro escolar compostelano en el aula vienen a confirmar un hecho que, tristemente, ya adelantábamos en la introducción, la enseñanza de la historia en los centros de Educación en España no atiende a los principios fundamentales de la EDH.

La rotundidad de esta afirmación se justifica en el hecho de que la creación y organización del currículo del área de Historia a lo largo de las diferentes leyes educativas aprobadas en España ha ignorado los principios pedagógicos propios de la EDH al continuar con un modo de enseñanza que promueve una visión puramente androcéntrica, y eurocéntrica, de la historia. Esto no ha cambiado con la LOMCE (2013), como bien muestra tanto el estudio del material dispuesto para las aulas de Historia, como la experiencia de los propios profesores.

El androcentrismo dominante en los materiales educativos de Historia, el currículo y el manual escolar, no solo importa un desconocimiento enorme al alumnado sobre la historia y el verdadero rol de la mujer en la historia, sino que a través de la relegación de la mujer a un papel secundario, muchas veces invisible, en la narración de los hechos históricos y en el uso de un lenguaje y unas imágenes determinadas, impulsa un modelo de enseñanza en el que perviven fuertemente los estereotipos de género, principales promotores de la desigualdad de género.

Esto es inadmisible en cualquiera área de la Educación, pero es especialmente preocupante en el área de una ciencia educativa como es la Historia, cuya naturaleza la hace idónea, y por tanto responsable, para la enseñanza de Derechos Humanos, puesto que su principal objetivo es, y debe ser, allegarnos al conocimiento profundo de la sociedad, tanto de nuestro pasado como de nuestro presente, promoviendo un pensamiento crítico en el individuo que le permita participar en la sociedad de manera íntegra, y siempre desde una posición de tolerancia e igualdad. Esto es y será imposible siempre y cuando se siga potenciando desde la Educación formal un entendimiento de la historia que no solo se encuentra alejado de la realidad de los hechos históricos, en este caso con relación al verdadero papel de la mujer en la historia, sino que promueve unos valores que otorgan a la mujer a un papel de subordinación frente al hombre. Lo que, por supuesto, afecta directamente al fomento significativo de los Derechos Humanos en el alumnado del sistema educativo español.

A razón de todo lo visto anteriormente, en pleno contexto de una nueva reforma educativa, y conscientes de que la EDH siempre ha sido una cuestión pendiente de todas y cada una de las leyes educativas habidas en España desde inicios de la democracia, es momento de reclamar a las autoridades competentes que esta nueva ley traiga consigo una verdadera reforma del rol que ocupa la EDH dentro de la Educación formal si realmente 
quiere ser efectiva. Para ello, no solo basta con otorgar el carácter de obligatoria a la materia de Educación en Valores Cívicos y Éticos (Torres Menárguez, 2020), sino que debe entenderse la EDH como una educación transversal, que afecta a todas y cada una de las áreas educativas, de modo que desde todo el sistema educativo se transmita al alumnado un mensaje conjunto y coherente en materia de EDH. De esta forma, deberá ser objeto de revisión profunda toda área de la Educación en aras de adecuarse a los fundamentos de la $\mathrm{EDH}$, pero más especialmente aquellas áreas cuya naturaleza las hace más propicias para la enseñanza de los Derechos Humanos, como es el caso de la Historia, o de la Filosofía.

\section{REFERENCIAS}

AMNISTIIA INTERNACIONAL (15 de enero del 2013): Educación para la ciudadanía y los derechos humanos. [Comunicado de prensa]. Recuperado de [Enlace].

AMNISTÍA INTERNACIONAL (s.f.): Educación en derechos humanos. Recuperado de [Enlace].

BARTON, K. (2010): "Historia e Identidad: el reto de los investigadores pedagógicos". En Metodología de investigación en didáctica de las Ciencias Sociales, pp.13-28. España: Institución Fernando el Católico.

BAYONA, B. (2013): "Los ejes de la LOMCE”. En Forum Aragón, 7, pp. 13-15

DE ALBA, N., GARCÍA, F., Y SANTIESTEBAN, A. (2012): "Educar para la participación ciudadana desde la enseñanza de las ciencias sociales”. En Educar para la participación ciudadana en la enseñanza de las Ciencias Sociales, pp. 10-16. España: Asociación Universitaria de Profesores de Didáctica de las Ciencias Sociales: Díada Editora.

DECRETO 86/2015, Diario Oficial de Galicia, 25 de junio de 2015.

FARRERAS, C. (4 de marzo de 2020): Las claves de la "ley Celaá", que busca "no dejar ningún alumno atrás”. La Vanguardia. Recuperado de [Enlace].

GARCÍA LUQUE, A. (2015): "Mujeres visibles e invisibles en la enseñanza de la Historia en la Educación Primaria: cambios y pervivencias al amparo de la LOMCE”. En Una Enseñanza de las Ciencias Sociales para el futuro. Recursos para trabajar la invisibilidad de personas, lugares y temáticas, pp. 163-173. España: Asociación Universitaria del Profesorado de Didáctica de las Ciencias Sociales: Díada Editora.

GÓNZALEZ, A. Y SANZ, R. (2016): "Desafíos y tensiones del sistema educativo del siglo XXI”. En Crónica, Revista Científico Profesional de la Pedagogía y de la Psicopedagogía, 1, pp. 5-18.

LOMLOE-Ministerio de Educación y Formación Profesional, 2020: [Enlace] 
LEY ORGÉNICA PARA LA MEJORA DE LA CALIDAD EDUCATIVA (LOMCE) (Ley Orgánica 8/2013, 9 de diciembre). Boletín Oficial del Estado, $n^{\circ}$ 295, 2013, 10 diciembre.

LÓPEZ FACAL, R Y VALLS, R. (2012): "La necesidad Cívica de saber Historia y Geografía”. En Educar para la participación ciudadana en la enseñanza de las Ciencias Sociales, pp. 185-192. España: Asociación Universitaria de Profesores de Didáctica de las Ciencias Sociales: Díada Editora.

MÉNENDEZ, M. (7 de enero de 2020): Pedro Sánchez es investido presidente por mayoría simple. Rtve.es. Recuperado de [Enlace].

MIRALLES, P., MOLINA, S., y ORTUÑO, J. (2011). "La Investigación en Didáctica de las Ciencias Sociales”. En Educatio Siglo XXI, 29 (1), pp. 149-174.

MONTES, R. (21 de enero de 2014): España, de nuevo a la cola de Europa en educación en derechos humanos. Eldiario.es. Recuperado de [Enlace].

PRESIDENCIA DE GOBIERNO (s.f.): Gobiernos desde la Legislatura Constituyente hasta la actualidad: Gobierno. Gobierno de España. Recuperado de [Enlace].

RAE (s.f.): Consultas lingüísticas. Diccionario de la lengua española. Recuperado de [Enlace].

TORRES MENÁRGUEZ, A. (4 de marzo de 2020): El Gobierno aprueba el proyecto de la nueva ley de educación que quita peso a la Religión. Elpaís.es. Recuperado de [Enlace].

PAGÈS, J. (1998). “Los valores y la didáctica de las Ciencias Sociales: retos para la formación de una conciencia democrática”. En Los valores y la didáctica de las Ciencias Sociales: Actas del IX Simposium de Didáctica de las Ciencias Sociales, pp. 7-20. España: Universitat de Lleida.

PAGÈS, J. (2009). “La competencia social y ciudadana”. En Aula de Innovación Educativa, 187, pp. 7-11.

PÉREZ LÓPEZ, A. (2011): El sexismo en los manuales escolares de Ciencias Sociales de la ESO (trabajo de maestría). Universidad de Almería, España. Recuperado de [Enlace].

PRATS, J. Y SANTACANA, J. (2011): “PPor qué y para qué enseñar Historia?”. En Enseñanza y aprendizaje de la Historia en la Educación básica, pp. 18-68. México: Secretaría de Educación Pública

PROYECTO DE LEY ORGÁNICA POR LA QUE SE MODIFICA LA LEY ORGÁNICA 2/2006 (LOMLOE). Boletín oficial del Estado, 121, 2020, 3 marzo.

SANT, E. Y PAGÈS, J. (2011): “¿Por qué las mujeres son invisibles en la enseñanza de la Historia?”. En Revista Historia y Memoria, 3, pp. 129-146.

UNESCO (2015): Replantear la educación ¿Hacia un bien común mundial? Recuperado de [Enlace]. 
VALLS, R., Y LÓPEZ FACAL, R. (2010): ¿¿Un nuevo paradigma para la enseñanza de la historia? Los problemas reales y las polémicas interesadas al respecto en España y en el contexto del mundo occidental”. En Enseñanza de las ciencias sociales: revista de investigación, 10, pp. 75-86.

VALERIO ULLOA, S. (noviembre de 2013): Eric Hobsbawn y la Historia Social. Un clásico que no pasa de moda [Conferencia]. Universidad de Guadalajara, México.

VEGA, C. (2002): "La mujer en la historia y la historia de las mujeres". En Mujer y educación: educar para la igualdad, educar desde la diferencia, pp. 13-20. España: Graó. 


\section{ANEXO}

Modelo de entrevista a profesores/as del departamento de Xeografía e Historia del Instituto Arcebispo Xelmirez I de Santiago de Compostela.

1. Según su experiencia, ¿Cuál es la presencia de la mujer en los contenidos designados por el currículo de la LOMCE para la asignatura de $4^{\circ}$ de ESO? ¿Considera que se trata de modo proporcionado a mujer y hombre en el relato histórico? ¿Por qué? ¿Y en el libro de texto empleado?

2. Alrededor del tratamiento que recibe la mujer en los contenidos de Historia, tanto en el currículo como en el manual escolar, y partiendo de su experiencia, me gustaría que respondiese y justificase las respuestas a las siguientes preguntas:

- ¿Considera que en el relato histórico desarrollado por el manual predomina una visión androcéntrica?

- ¿Piensa que a través de los contenidos dispuestos por el currículo y por el manual el alumnado puede obtener un conocimiento adecuado sobre el papel de la mujer en la Historia Contemporánea universal?

3. ¿Ha añadido o modificado algunos o todos los contenidos que existen en el libro con respecto al papel de la mujer en la Historia? ¿Por qué?

4. Solo si usted lo considerara necesario, y atendiendo únicamente al diseño del currículo oficial de Historia por parte de las autoridades gubernamentales competentes ¿Qué consideraría necesario reformar en el diseño del área de Historia para revertir el determinado tratamiento que recibe la mujer en el relato histórico? 